\title{
Higher Intake of Milk-Replacer Pre-Weaning Enhances Post-Weaning Insulin-Like Growth Factor 1 Levels in Japanese Black Cattle
}

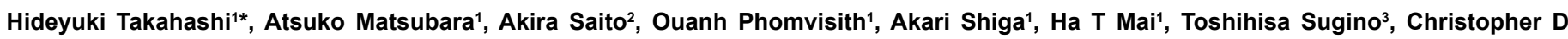
McMahon ${ }^{4}$, Tetsuji Etoh ${ }^{1}$, Yuji Shiotsuka1, Ryoichi Fujino ${ }^{1}$, Mitsuhiro Furuse $^{1}$ and Takafumi Gotoh ${ }^{1 *}$

${ }^{1}$ Kuju Agricultural Research Center, Kyushu University, 878-0201 Kuju-cho, Oita, Japan

2Zenrakuren, Shiba 4-17-5, Minato-ku, 108-0014 Tokyo, Japan

${ }^{3}$ Graduate School of Biosphere Science, Hiroshima University, Higashi-Hiroshima, Higashi-Hiroshima-shi, 739-8528 Hiroshima, Japan

${ }^{4}$ AgResearch Ltd, Private Bag 3123, Hamilton, New Zealand

\begin{abstract}
Alterations in early pre-natal nutrition of Japanese Black calves influence the glucose and lipid metabolism after weaning. However, the effects of early nutritional status on the endocrine system in later life stages in Japanese Black cattle are unknown. This study examined how post-weaning plasma levels of growth hormone (GH), insulin-like growth factor 1 (IGF-1), and blood insulin, which are hormones affecting growth and meat quality, and metabolites were affected by feeding $1800 \mathrm{~g}$ versus $500 \mathrm{~g}$ of milk replacer to Japanese Black cattle (5 per group) during nursing. Up to weaning (90 days post-birth), all calves received calf starter and hay ad libitum, and post-weaning, they received a concentrate feed and hay ad libitum. Plasma concentrations of GH and IGF-1 were greater at weaning in the high-milk-replacer group ( $P<0.1$ and $P<0.01$, respectively), and elevated IGF-1 concentrations persisted until the study end $(210 \mathrm{~d})(P<0.05)$, suggesting that the levels were sustained independent of the influences of both $\mathrm{GH}$ and nutrient intake. Blood insulin and metabolites (plasma glucose, beta-hydroxybutyric acid, and non-esterified fatty acids) were not significantly different between the two groups. The results of this study suggest that feeding calves a high volume of milk replacer during nursing will increase IGF-1 secretion well beyond weaning.
\end{abstract}

Keywords: Japanese Black cattle; Growth hormone; Insulin-like growth factor 1; Milk replacer; Ruminant growth rate

Abbreviations: GH: Growth hormone; IGF-1: Insulin-like growth factor 1; CP: Crude protein; CF: Crude fat; TDN: Total digestible nutrients; TR-FIA: Time-resolved fluoroimmunoassay.

\section{Introduction}

Nutrient composition and availability during the early growth phase affects tissue composition and metabolism at adulthood in mammals [1]. A high plane of nutrition during the initial growth phase affects meat quantity and quality in 10-mo-old crossbred steers (Japanese Black male $\times$ Holstein female) [2]. In addition, feeding high quantities of milk to Japanese Black cattle until $150 \mathrm{~d}$ of age increases post-weaning growth, glucose concentrations and lipid metabolism [3]. However, there is a lack of information about the effect of a high plane of nutrition pre-weaning on the endocrine system in post-weaning of Japanese Black cattle.

In ruminants, changes to the nutritional status and nutrient intake of feed alter hormone secretion [4,5]. Specifically, increased concentrations of growth hormone $(\mathrm{GH})$ trigger the secretion of insulin-like growth factor 1 (IGF-1) in rats [6,7] and in beef cattle [8]. Increased concentrations of both hormones in blood are linked to muscle growth and, thus, the amount of lean meat in cattle $[9,10]$. Based on the afore mentioned findings, we hypothesized that a high plane of nutrition offered pre-weaning might affect post-weaning secretion of GH and IGF-1 in Japanese Black cattle. Previously, we reported positive correlations between the pre-weaning period of nutrition, plasma insulin and blood metabolite levels (plasma glucose, betahydroxybutyric acid [ $\beta$-HBA], non-esterified fatty acids [NEFAs]) and post-weaning growth rate in these calves $[2,3]$. Therefore, in this study, we sought to assess how a high-nutrient feed affects the relationship between hormones, blood metabolites and growth rate.

\section{Materials and Methods}

\section{Experimental animals}

All experimental procedures, including animal care and handling, were performed in accordance with guidelines from the Committee for Animal Welfare of Kyushu University.

Ten Japanese Black male calves were randomly assigned to two groups. The calves of both groups were fed milk replacer containing $26 \%$ crude protein (CP), $25.5 \%$ crude fat (CF) and $116 \%$ total digestible nutrients (TDNs). The quantity of milk replacer was determined according to a previous study [3]. Five control calves (initial body weight; $32.7 \pm 1.19$ ) were provided with $500 \mathrm{~g} / \mathrm{d}$ of milk replacer from 14 to $90 \mathrm{~d}$ of age. Five calves in the experimental group (initial body weight; $33.6 \pm 1.90$ ) received $800 \mathrm{~g} / \mathrm{d}$ until $14 \mathrm{~d}$ of age. Between 4 and 27 $\mathrm{d}$, the amount of milk replacer was progressively increased to $1800 \mathrm{~g} / \mathrm{d}$ and maintained at this level until $72 \mathrm{~d}$. From 73 to $85 \mathrm{~d}$, milk replacer was gradually reduced to $800 \mathrm{~g} / \mathrm{d}$, where it remained until weaning at

*Corresponding authors: Hideyuki Takahashi, Kuju Agricultural Research Center, Kyushu University, 878-0201 Kuju-cho, Oita, Japan, Tel: +81974761377; Fax: +81974761218; E-mail: takahashi@farm.kyushu-u.ac.jp

Takafumi Gotoh, Kuju Agricultural Research Center, Kyushu University, 8780201 Kuju-cho, Oita, Japan, Tel: +81974761377; Fax: +81974761218; E-mail: gotoh@farm.kyushu-u.ac.jp

Received December 16, 2016; Accepted December 28, 2016; Published December 30, 2016

Citation: Takahashi H, Matsubara A, Saito A, Phomvisith O, Shiga A, et al. (2016) Higher Intake of Milk-Replacer Pre-Weaning Enhances Post-Weaning Insulin-Like Growth Factor 1 Levels in Japanese Black Cattle. J Vet Sci Technol 8: 409. doi: 10.4172/2157-7579.1000409

Copyright: @ 2016 Takahashi H, et al. This is an open-access article distributed under the terms of the Creative Commons Attribution License, which permits unrestricted use, distribution, and reproduction in any medium, provided the original author and source are credited. 
$90 \mathrm{~d}$. Both experimental and control calves were fed calf starter (TDN, $72 \%$; CP, $18 \%$; ether extract, $2 \%$ ) from 30 to $90 \mathrm{~d}$. Between 90 to $210 \mathrm{~d}$, calves were fed concentrate (CP, $16 \%$; $\mathrm{CF}, 2.5 \%$; TDN, $68 \%)$. The calves and cattle were fed concentrate at quantities necessary for individual weight gain of $1 \mathrm{~kg} / \mathrm{d}$, as recommended by the Japanese Feeding Standard for Beef Cattle [11] and hay (CP, 13.4\%; CF, 3.6\%; TDN, $59.3 \%$ ) ad libitum. Body weight was measured at 90 and $210 \mathrm{~d}$ of age.

\section{Blood samples}

The secretion of GH in cattle is pulsatile [12]; therefore, a single blood sample may not reflect the average concentration of $\mathrm{GH}$ in blood. To reduce variability, we took advantage of the fact that $\mathrm{GH}$ release is synchronized around feeding, with a burst immediately prior, followed by no secretion during or for at least $1 \mathrm{~h}$ after feeding [13]. Therefore, we collected blood samples to coincide with the pre-feeding secretory episode.

Blood samples were collected from the jugular vein into heparinized tubes with aprotinin (500 kallikrein inhibitory units $/ \mathrm{mL}$ of blood; Sigma-Aldrich Inc., Tokyo, Japan) before calves were provided their morning feed at 90,150 , and $210 \mathrm{~d}$ of age. Blood samples were centrifuged at $2330 \times \mathrm{g}$ at room temperature for $30 \mathrm{~min}$ and stored at $-40^{\circ} \mathrm{C}$ until analysis. Concentrations of GH and IGF-1 were measured using a time-resolved fluoroimmunoassay (TR-FIA) as previously described $[4,14]$. Intra- and inter-assay coefficients of variability (CVs) for GH were $2.6 \%$ and $3.6 \%$, respectively; for IGF-1, they were $6.9 \%$ and $5.5 \%$, respectively. The lowest detectable doses of GH and IGF-1 in this assay were $0.158 \mathrm{ng} / \mathrm{mL}$ and $0.053 \mathrm{ng} / \mathrm{mL}$, respectively. Insulin, glucose, $\beta$-HBA and NEFA concentrations were measured, respectively, with a bovine insulin enzyme-linked immunosorbent assay kit (Mercodia, Uppsala, Sweden), glucose oxidase enzymatic method (glucose B-test; Wako Pure Chemical, Osaka, Japan), $\beta$-HBA enzyme-linked immunosorbent assay kit (Cusabio Biotech, Wuhan, China), and acyl-CoA synthetase-acyl-CoA oxidase enzymatic method (FFAC; Wako Pure Chemical Industries Ltd., Osaka, Japan), following manufacturer protocols.

\section{Statistical analyses}

Body weight gain, milk replacer, $\mathrm{CP}$ and $\mathrm{CF}$ intake, and plasma GH and IGF-1 concentrations are presented as mean \pm SEM. StatView 5 (SAS Institute Inc., Cary, NC, USA) was used for statistical analyses of GH and IGF-1 concentrations. Post-hoc comparisons between the control and experimental groups were performed with two-tailed, unpaired Student's t-tests. Data for GH, IGF-1, and insulin and blood metabolite profiles were analyzed using the MIXED procedure in SAS (SAS Institute Inc.) in which the treatment was a fixed effect while cattle and feeding period were random effects. For statistical analyses of plasma hormones and metabolite concentrations, the interaction of sampling time by treatment was added to the model.

\section{Results and Discussion}

At $90 \mathrm{~d}$, mean concentrations of $\mathrm{GH}$ tended to be higher in the experimental group than in the controls $(P<0.1)$, but these differences disappeared by 150 and $200 \mathrm{~d}$ of age (Figure 1a). Overall, concentrations of $\mathrm{GH}$ varied with dietary treatment $(\mathrm{P}=0.03)$ and age $(P<0.01)$, although the interaction of age and treatment was not significant $(P=0.15)$ (Figure 1a). These results are in accordance with previous reports wherein changing the amount of milk replacer have little influence concentrations of GH in nursing Holstein bull calves [15], but that basal and growth hormone-releasing hormone (GHRH)-induced GH concentrations decline with age in dairy cattle

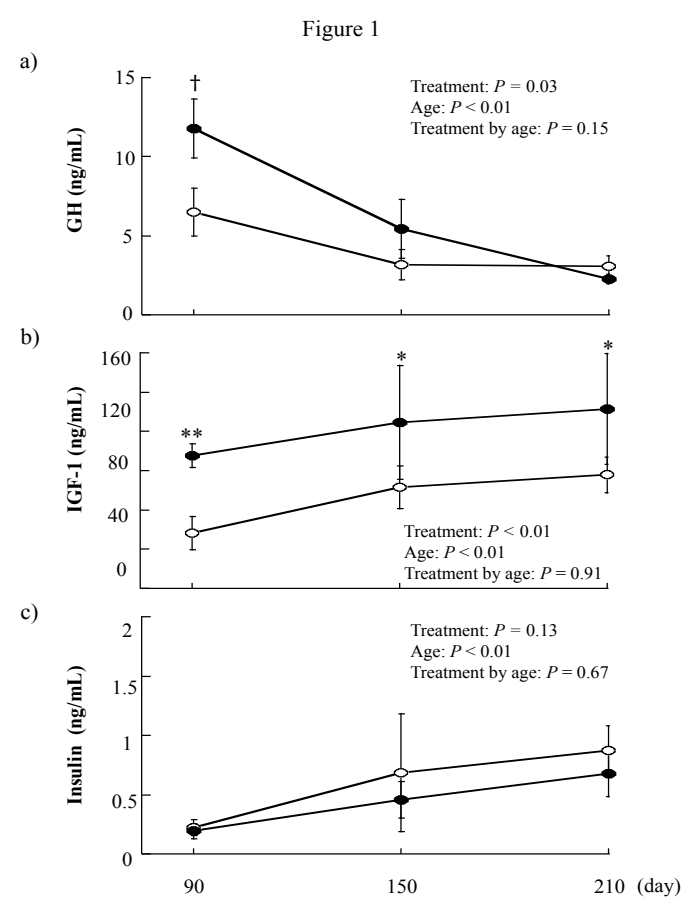

Figure 1: Plasma concentrations of (a) growth hormone $(\mathrm{GH})$, (b) insulin-like growth factor 1 (IGF-1), and (c) insulin in control (०) and experimental (•) groups at 90,150 , and $210 \mathrm{~d}$ of age. Values are means \pm SEM ( $n=5 /$ group) ${ }^{* *} P<0.01 ;{ }^{*} P<0.05 ; \dagger P<0.1$.

[16]. Therefore, age may influence the secretion of GH more than the amount of milk consumed in nursing and just-weaned calves.

Plasma concentrations of IGF-1 were significantly greater in the experimental group than in the controls at all measured time points $(P<0.05$; Figure $1 \mathrm{~b})$. Moreover, although total intake of CP did not differ between the two groups at $90 \mathrm{~d}$, experimental animals had a higher intake of CP from the milk replacer than the control animals $(P<0.01$; Table 1). Our findings are in agreement with work showing that both GH and dietary CP regulate secretion of IGF-1 in beef cattle [8]. The increased concentrations of IGF-1 in the experimental calves could thus be attributed to increased protein content ingested from the highmilk-replacer diet, which is easily digested and absorbed (compared with other protein sources such as soy), resulting in superior calf performance (in male Holsteins; [17]). However, we also found that experimental calves maintained higher concentrations of IGF-1 after weaning $(P<0.01)$. Additionally, concentrations of IGF-1 increased in both groups with age $(P<0.01)$, but there was no age by treatment interaction $(P=0.91)$ (Figure 1b). Given the lack of differences in $\mathrm{GH}$ concentrations and $\mathrm{CP}$ intake after weaning between the two groups (Table 1 and Figure 1a), these data suggest that GH and CP intake may actively regulate IGF-1 secretion during nursing while also priming an independent mechanism to maintain post-weaning secretion. Our previous studies similarly revealed that a high volume of milk replacer fed to nursing calves influenced both meat quality and the expression of genes related to post-weaning nutrient metabolism $[3,18,19]$.

Moreover, research in humans has shown that individuals that were fed milk replacer during infancy ingested more protein and exhibited higher IGF-1 concentrations at 6 mo compared with breastfed individuals [19]. A subsequent study confirmed the influence of early-life protein consumption: infants fed high-protein milk replacer had higher concentrations of IGF-1 in blood compared with 
Citation: Takahashi H, Matsubara A, Saito A, Phomvisith O, Shiga A, et al. (2016) Higher Intake of Milk-Replacer Pre-Weaning Enhances PostWeaning Insulin-Like Growth Factor 1 Levels in Japanese Black Cattle. J Vet Sci Technol 8: 409. doi: 10.4172/2157-7579.1000409

Page 3 of 4

\begin{tabular}{|c|c|c|}
\hline & Control & Experimental \\
\hline Body weight (at $90 \mathrm{~d}, \mathrm{~kg}$ ) & $90.8 \pm 4.80$ & $118.7 \pm 8.33^{*}$ \\
\hline Body weight (at $210 \mathrm{~d}, \mathrm{~kg}$ ) & $226.6 \pm 9.51$ & $249.2 \pm 13.90$ \\
\hline Average daily gain $(\mathrm{kg} / \mathrm{d})$ & $0.92 \pm 0.04$ & $1.03 \pm 0.06$ \\
\hline \multicolumn{3}{|l|}{ Pre-weaning (0-90 d, kg) } \\
\hline \multicolumn{3}{|l|}{ Milk replacer intake } \\
\hline DM & $38.26 \pm 0.57$ & $93.94 \pm 6.97^{\star *}$ \\
\hline $\mathrm{CP}$ & $9.95 \pm 0.15$ & $24.42 \pm 1.81^{* *}$ \\
\hline $\mathrm{CF}$ & $9.76 \pm 0.15$ & $23.95 \pm 1.78^{\star \star}$ \\
\hline \multicolumn{3}{|l|}{ Calf starter intake } \\
\hline DM & $59.56 \pm 3.15$ & $18.21 \pm 1.29^{* *}$ \\
\hline $\mathrm{CP}$ & $10.72 \pm 0.57$ & $3.28 \pm 0.23^{\star *}$ \\
\hline $\mathrm{CF}$ & $1.19 \pm 0.10$ & $0.36 \pm 0.03^{* *}$ \\
\hline \multicolumn{3}{|l|}{ Hay intake } \\
\hline DM & $31.97 \pm 1.69$ & $14.84 \pm 1.05^{* *}$ \\
\hline$C P$ & $4.28 \pm 0.23$ & $1.98 \pm 0.14^{\star *}$ \\
\hline $\mathrm{CF}$ & $1.15 \pm 0.06$ & $0.53 \pm 0.04^{* *}$ \\
\hline \multicolumn{3}{|l|}{ Total intake } \\
\hline CP & $24.95 \pm 0.77$ & $29.69 \pm 2.18$ \\
\hline $\mathrm{CF}$ & $12.10 \pm 0.17$ & $24.85 \pm 1.84^{\star \star}$ \\
\hline \multicolumn{3}{|l|}{ Post-weaning (90-210 d, kg) } \\
\hline DM & $344.2 \pm 14.40$ & $346.5 \pm 19.30$ \\
\hline CP & $62.58 \pm 2.63$ & $63.01 \pm 3.51$ \\
\hline $\mathrm{CF}$ & $9.78 \pm 0.41$ & $9.85 \pm 0.55$ \\
\hline \multicolumn{3}{|l|}{ Hay intake } \\
\hline DM & $228.7 \pm 9.6$ & $263.2 \pm 14.7$ \\
\hline $\mathrm{CP}$ & $36.6 \pm 1.53$ & $42.1 \pm 2.35$ \\
\hline $\mathrm{CF}$ & $9.83 \pm 0.41$ & $11.3 \pm 0.63$ \\
\hline \multicolumn{3}{|l|}{ Total intake } \\
\hline $\mathrm{CP}$ & $99.15 \pm 4.16$ & $105.09 \pm 5.86$ \\
\hline $\mathrm{CF}$ & $19.60 \pm 0.82$ & $21.15 \pm 1.18$ \\
\hline
\end{tabular}

Table 1: Average weight gain and daily intake of Japanese Black calves fed milk replacer, calf starter, concentrate, and hay as well as nutritional components (CP and CF). DM: Dry matter; CP: Crude protein; CF: Crude fat; Data for feed intake are expressed as the mean $\pm \operatorname{SEM}(n=5) .{ }^{* *} P<0.01,{ }^{*} P<0.05$

those fed low-protein milk replacer, and elevated concentrations of IGF-1 persisted through to adolescence [20]. Together, current and previous observations are consistent with nutritional programming, a phenomenon wherein nursing-diet quality or quantity (e.g., more high-protein milk replacer) has a persistent post-weaning effect [21]. Future studies should, therefore, focus on elucidating the mechanisms underlying the nutritional programming of IGF-1 secretion in Japanese Black cattle, specifically verifying the potential link with a high-milkreplacer diet during nursing.

In the current study, concentrations of insulin did not differ between the two groups $(P=0.13)$, although it did vary with age $(P<0.01)$, and the age by treatment interaction was not significant $(P=0.67)$ (Figure 1c). Thus, the observed changes were the result of age alone. Our results are in accordance with previous work showing a positive correlation between age and insulin concentrations in the blood of Japanese Black cattle [22].

Calves in the experimental group weighed more than control calves at $90 \mathrm{~d}$, although these differences disappeared by $210 \mathrm{~d}$ (Table 1). Moreover, a higher amount of milk appeared to have negligible effects on blood metabolite concentrations (Figure 2). In contrast, our previous study showed that feeding high volumes of milk replacer to nursing Japanese Black cattle increased growth performance and blood metabolite (glucose, $\beta$-HBA, NEFA) concentrations compared with the control (data not shown). Post-weaning up-regulation of glucose/ a)

Figure 2

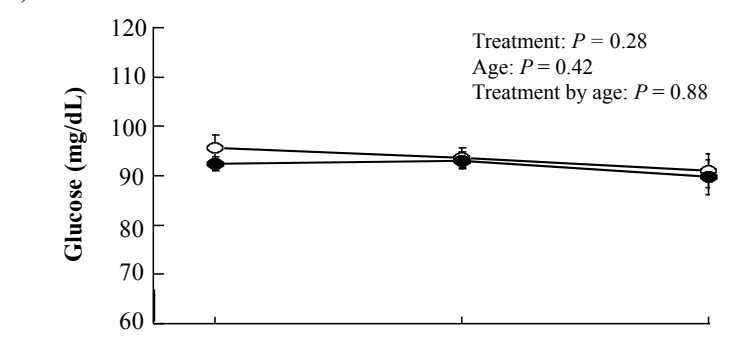

b)

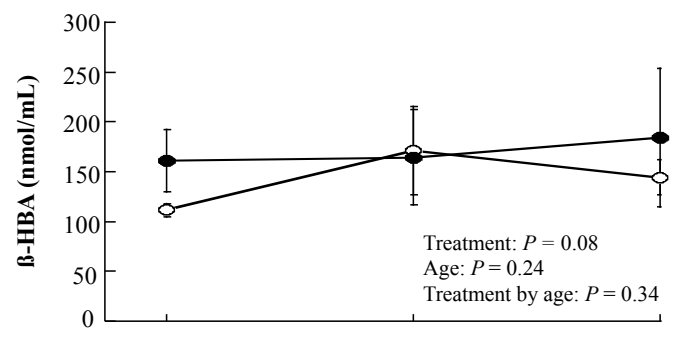

c)

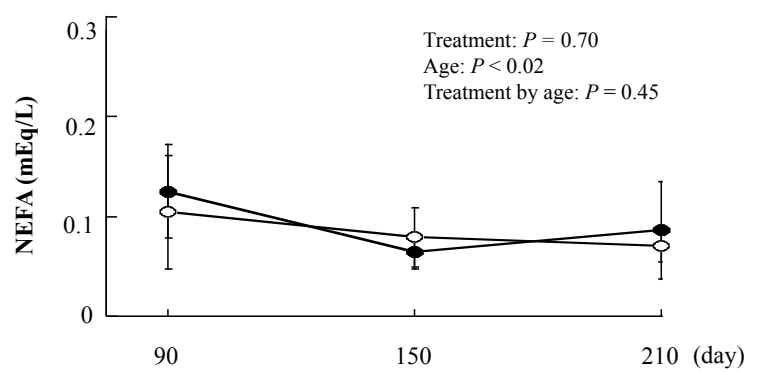

Figure 2: Plasma concentrations of (a) glucose, (b) beta-hydroxybutyric acid ( $\beta$-HBA), and (c) non-esterified fatty acids (NEFAs) in control $(\circ)$ and experimental $(\bullet)$ groups at 90,150 , and $210 \mathrm{~d}$ of age. Values are means \pm SEM ( $n=5 /$ group)

lipid-metabolism-related gene expression subsequently decreased blood metabolites in the experimental group [3]. These differences may be due to variations in feeding periods; calves received a highmilk-replacer diet for $48 \mathrm{~d}$ over the 90 -d feeding period in this study, whereas they received milk replacer for $90 \mathrm{~d}$ over a $150-\mathrm{d}$ feeding period in Matsubara et al. [3]. These results combined suggest that a 48-d maximum nursing period is not sufficient and that the duration should be extended beyond $90 \mathrm{~d}$ to improve the growth performance, as well as glucose and lipid metabolism, of Japanese Black calves.

Although we had previously demonstrated that a high-milkreplacer treatment increased concentrations of $\beta$-HBA and NEFA (data not shown), we did not observe a significant difference in lipid concentrations between groups in this study despite high $\mathrm{CF}$ intake during nursing (Figures $2 \mathrm{~b}$ and $2 \mathrm{c}$ ). Equivocal results from fat-supplemented diets have been reported elsewhere. For example, such diets increased concentrations of $\beta$-HBA and NEFA in some dairy cattle (Holstein cows [23]), but not in others [24]. Given these inconsistent effects of CF intake on concentrations of $\beta$-HBA and NEFA, further research is required to explore how milk fat influences lipid metabolism in calves.

In conclusion, a high milk-replacer diet more strongly affected plasma IGF-1 concentrations than GH concentrations in Japanese Black cattle. Furthermore, the plane of nutrition during nursing may program post-weaning regulation and secretion of IGF-1 resulting in 
Citation: Takahashi H, Matsubara A, Saito A, Phomvisith O, Shiga A, et al. (2016) Higher Intake of Milk-Replacer Pre-Weaning Enhances PostWeaning Insulin-Like Growth Factor 1 Levels in Japanese Black Cattle. J Vet Sci Technol 8: 409. doi: 10.4172/2157-7579.1000409

Page 4 of 4

prolonged or permanent changes to secretion patterns. Further studies are warranted to determine the mechanisms by which IGF-1 secretion is maintained in ruminants fed high volumes of milk replacer and whether such changes affect body composition at maturity. Data from this study provides direction for the effective regulation of early feeding regimes to improve meat quantity and quality in the cattle industry.

\section{Acknowledgements}

We thank Dr. AF Parlow and the National Hormone and Pituitary Program at the National Institute of Diabetes and Digestive and Kidney Diseases (NIDDK) for bovine $\mathrm{GH}$ protein and antibodies. This study was supported by Zenrakuren, Japan and Ito-Kinen-Zaidan, Japan.

\section{References}

1. Sinclair KD, Lea RG, Rees WD, Young LE (2007) The developmental origins of health and disease: current theories and epigenetic mechanisms. Soc Reprod Fertil Suppl 64: 425-443.

2. Ebara F, Inada S, Morikawa M, Asaoka SH, Isozaki Y, et al. (2013) Effect of nutrient intake on intramuscular glucose metabolism during the early growth stage in cross-bred steers (Japanese Black male $\times$ Holstein female). J Anim Physiol Anim Nutr 97: 684-693.

3. Matsubara A, Takahashi H, Saito A, Nomura A, Sithyphone K, et al. (2016) Effects of a high milk intake during the pre-weaning period on nutrient metabolism and growth rate in Japanese Black cattle. Anim Sci J 87: $1130-1136$.

4. Takahashi $H$, Kurose $Y$, Suzuki Y, Kojima M, Yamaguchi T, et al. (2009) Ghrelin differentially modulates the $\mathrm{GH}$ secretory response to $\mathrm{GHRH}$ between the fed and fasted states in sheep. Domest Anim Endocrinol 37: 55-60.

5. Laarman AH, Ruiz-Sanchez AL, Sugino T, Guan LL, Oba M (2012) Effects of feeding a calf starter on molecular adaptations in the ruminal epithelium and liver of Holstein dairy calves. J Dairy Sci 95: 2585-2594.

6. Roberts CT Jr, Brown AL, Graham DE, Seelig S, Berry S, et al. (1986) Growth hormone regulates the abundance of insulin-like growth factor I RNA in adult rat liver. J Biol Chem 261: 10025-10028.

7. Isgaard J, Nilsson A, Vikman K, Isaksson OGP (1989) Growth hormone regulates the level of insulin-like growth factor-I mRNA in rat skeletal muscle. $J$ Endocrinol 120: 107-112.

8. Elsasser TH, Rumsey TS, Hammond AC (1989) Influence of diet on basal and growth hormone-stimulated plasma concentrations of IGF-I in beef cattle. J Anim Sci 67: 128-141.

9. Florini JR, Ewton DZ, Coolican SA (1996) Growth hormone and the insulin-like growth factor system in myogenesis. Endocr Rev 17: 481-517.

10. Gotoh T, Takahashi H, Nishimura T, Kuchida K, Mannen H (2014) Meat produced by Japanese Black cattle and Wagyu. Anim Front 4: 46-54.
11. Agriculture, Forestry and Fisheries Research Council Secretariat, Ministry of Agriculture, Forestry and Fisheries (MAFF) (2000) Available from URL: http:// www.maff.go.jp/e/

12. Gluckman PD, Breier BH, Davis SR (1987) Physiology of the somatotropic axis with particular reference to the ruminant. J Dairy Sci 70: 442-466.

13. McMahon CD, Radcliff RP, Lookingland KJ, Tucker HA (2001) Neuroregulation of growth hormone secretion in domestic animals. Domestic Animal Endocrinology 20: 65-87.

14. Sugino T, Hasegawa Y, Kikkawa Y, Yamaura J, Yamagishi M, et al. (2002) A transient ghrelin surge occurs just before feeding in a scheduled meal-fed sheep. Biochem Biophys Res Comm 295: 255-260.

15. Quigley JD, Wolfe TA, Elsasser TH (2006) Effects of additional milk replacer feeding on calf health, growth, and selected blood metabolites in calves. J Dairy Sci 89: 207-216.

16. Hodate K, Johke T, Kawabata A, Fuse H, Ohashi S (1988) Age-associated changes in bovine growth hormone release via human growth-releasing factor Japanese J Zootech Sci 59: 285-291.

17. Silva AG, Huber JT, DeGregorio RM (1986) Influence of substituting two types of soybean protein for milk protein on gain and utilization of milk replacers in calves. J Dairy Sci 69: 172-180.

18. Gotoh T (2010) Metabolic imprinting effects in grass-fed Wagyu (Japanese Black) beef production. FASEB 24: 90-94.

19. Scheffler JM, McCann MA, Greiner SP, Jiang H, Hanigan MD, et al. (2014) Early metabolic imprinting events increase marbling scores in fed cattle. J Anim Sci 92: 320-324.

20. Socha P, Janas R, Dobrzañska A, Koletzko B, Broekaert I, et al. (2005) Insulin like growth factor regulation of body mass in breastfed and milk formula fed infants. Data from the EU Childhood Obesity Programme. Adv Exp Med Bio 569: 159-163.

21. Larnkjaer A, Ingstrup HK, Schack-Nielsen L, Hoppe C, Mølgaard C, et al. (2009) Early programming of the IGF-1 axis: negative association between IGF-1 in infancy and late adolescence in a 17 year longitudinal follow-up study of healthy subjects. Growth Horm IGF Res 19: 82-86.

22. Martin PM, Holly JM, Smith GD, Ness AR, Emmett P, et al. (2005) Could associations between breastfeeding and insulin-like growth factors underlie associations of breastfeeding with adult chronic disease? The Avon Longitudinal Study of Parents and Children. Clin Endocrinol 62: 728-737.

23. Matsuzaki M, Takizawa S, Ogawa M (1997) Plasma insulin, metabolite concentrations, and carcass characteristics of Japanese Black, Japanese Brown, and Holstein steers. J Anim Sci 75: 3287-3293.

24. Skaar TC, Grummer RR, Dentine MR, Stauffacher RH (1989) Seasonal effects of prepartum and postpartum fat and niacin feeding on lactation performance and lipid metabolism. J Dairy Sci 72: 2028-2038. 